\title{
LOS DESTINOS DEL OBJETO
}

\author{
Bettina Miglierina \\ Psicóloga de la UDELAR
}

Profesora adjunta del IUPA

Miembro de la AUDEPP

Correo electrónico: bmiglierina@adinet.com.uy

ORCID: 0000-0002-1412-3381 


\section{Resumen}

Las figuras teóricas internalizadas que se entretejen en nuestro pensar se diluyen sorprendentemente cuando asistimos a relatos de lo mentalmente inasible. El sujeto, ese otro a quien escuchamos, despliega lo que podríamos denominar, informalmente, como su dragón: manifestación o acto de violencia, agresión, que no encontró a su paso obstáculo alguno que la detuviera.

En este artículo me referiré a lo que se me presentó como un intento de filicidio. ¿Cómo y desde dónde nos interpela una situación clínica marcada por este hecho? El psicoanálisis, desde siempre llamado a articular la interacción de lo intrapsíquico y lo intersubjetivo, parece desafiado a analizar esa relación desde ejes más específicos.

La pulsión, nunca descuidada en nuestras descripciones del funcionamiento psíquico, aparece con fuerza convocada en esta ocasión. ¿Cuál el destino de las investiduras cuando pudo haberse concretado un filicidio? Siguiendo algunas ideas de André Green acerca de la ligazón objetal, abordaré el análisis de un material que ubica intensamente a la clínica como soberana a la hora de conducir nuestras reflexiones

Palabras clave: investiduras, ligazón objetal, desobjetalización, destructividad

\section{DESTINATIONS OF THE OBJECT}

\section{Abstract}

The internalized theoretical figures that are intertwined in our thoughts are surprisingly diluted when we witness stories of the unthinkable. The subject, that Other that we listen to, deploys what we could define, informally, as his or her dragon: a manifestation or an act of violence, aggression, something that did not find in its path an obstacle that would stop it.

In this article, I will refer to what is presented to me as an attempt of filicide.

¿How and where from does a clinical situation marked by this fact question us? Psychoanalysis, always called on to articulate the interaction of the intrapsychic and the intersubjective, seems challenged to analyze this relationship from more specific lines of action.

The never neglected drive in our descriptions of psychical functioning appears, summoned with strength in this occasion. ¿What's the role of the investitures when a filicide could have taken place?

Following some of André Green's ideas about objetal connection, I approach the analysis of a material that places clinical practice at its center at the time of reflecting.

Keywords: investitures, objectal connection, desobjectalization, destructiveness 


\section{PRESENTACIÓN DEL CASO}

A veces, las figuras actuales de la violencia parecen delinearse desde trazos inimaginables. En efecto, Patricia, de 32 años, concurre a la consulta con indicación de psicodiagnóstico y una derivación escrita en la cual se lee: «Intento de filicidio». Sus primeras palabras son: «Me mandaron del juzgado»; se trata de una imputada en un proceso judicial en curso.

A continuación, ordeno algunos datos para aproximarnos a un entendimiento de las circunstancias.

\section{Datos de su pasado}

Sus padres se separaron cuando Patricia tenía 2 años. No vio más a su padre. Fue a vivir con su abuela y su hermana menor durante unos años, y luego volvió a vivir con su madre, un nuevo compañero de esta y subsiguientes hermanos menores.

- Sobre su madre menciona severa inestabilidad y recuerda que «podía ser muy alegre y muy agresiva». Refiere situaciones de maltrato, peleas caóticas, reacciones explosivas de hostilidad, propias y ajenas, en su entorno más próximo. Su infancia y adolescencia transcurrió en un ir y venir, una convivencia alternante con distintos familiares. Y siempre, tarde o temprano, con un retorno al conflictivo ámbito materno. Afirma: «Siempre tuve un amor infinito por mi madre», pero relata una relación marcada por afectos tempestuosamente cambiantes y distanciamientos desgarradores. 
- Los vínculos de pareja se dan con uniones fuertes y finales disruptivos, impregnados de hostilidad. No se describen desde un aspecto de construcción de su afectividad ni de su historicidad. Solo en tanto hechos.

\section{Datos de la actualidad}

- Patricia tiene dos hijos de distintos padres: Cecilia (15 años) y Juan (8 años). También vive con Camila, hija del padre de su segundo hijo. Camila y Juan son, por tanto, hermanos por parte de padre.

- Patricia se había separado del padre de Juan (Luis) porque peleaban mucho, ambos se agredían verbal y físicamente. Mediaba una causa judicial por violencia doméstica, con medidas cautelares vigentes.

- Cuando llega a consultar, Patricia salía con otro novio.

- Camila era como una hija para ella, a la que «le daba todo», refiriéndose a que no permitía que tuviera carencias económicas. Ya estaban hablando de los preparativos de la fiesta de 15 años que la chica anhelaba. Patricia vivió y compartió más tiempo con Camila que con su propia hija Cecilia, que muchas veces fue dejada a cargo de su abuela.

\section{Hechos}

- Camila va a visitar a su madre biológica y muere electrocutada en un accidente.

- Cuando llega la noticia, Patricia se desborda, reacciona estrepitosamente en el dolor: «Me puse como loca».

- Cecilia va con ella al velatorio y entierro de Camila. Juan se queda en su casa, a cargo de la persona que habitualmente lo cuidaba, sin saber nada de lo que había pasado.

- Respecto a la muerte de Camila, Patricia refiere: 
Yo costeé todo el velorio de Camila. Le compré el vestido de fiesta [de 15] que ella quería, para que se lo pusieran para el velatorio y la maquillaran. Vi cosas que me llenaban de rabia, de quienes decían que ella no era de la familia. Me daban ganas de sacarlos a todos para afuera. En el cementerio no me quería ir, no la quería soltar.

- Al regresar a su casa, Patricia se acuesta, solo quería dormir. Menciona: «No quería estar en la realidad».

- Juan, ante ese panorama y sin saber lo que sucedía, pregunta por Camila y dice que tiene miedo. Patricia llama a Luis y le propone volver a la relación y cancelarle la restricción existente para «que viniera a hacerse cargo del niño». Mientras tanto, Juan estaba allí y, al ver mal a su madre, se le acerca. Patricia relata:

Me acariciaba, me preguntaba qué me pasaba, se acostaba ahí conmigo. Preguntaba por Camila porque veía que habíamos vuelto sin ella. Le dije que se tenía que acostumbrar porque ahora Camila estaba en el cielo. Él gritaba, se puso muy mal, lloraba. Cecilia no tomaba su medicación [psiquiátrica] y la amenacé: «Mañana te llevo al médico». Juan me dice: «Vos sos mala». Estaban todos en la casa; yo en el cuarto estaba sola con él. Las pastillas que le dan a Cecilia lo pueden calmar a él. Y le di.

No da más detalles al respecto ni hace otros comentarios. Luego dice: «Me despierto cuando Cecilia gritaba: “¡Lo mató! ¡Lo mató!”. Y ya el padre se lo lleva a emergencia. Vino la policía y me desacaté».

- Inmediatamente Juan es internado en сті у, por orden judicial, se asigna su tenencia a un familiar materno. Su madre solo puede visitarlo en presencia de un tercero. 


\section{Algunas observaciones}

- La presentación de la paciente es la esperable para su edad, con un aspecto personal cuidado, arreglado y actual.

- Desarrolla un discurso que conserva la coherencia secuencial y el hilo conductor.

- No surgen mayores enfatizaciones emocionales. No se angustia en el curso de sus narraciones. Sus planteos remiten fundamentalmente a lo fáctico y casi nada a lo vivencial. No despliega un cuestionamiento introspectivo respecto a la gravedad de lo sucedido ni una reconsideración de las situaciones de vida que pudieron haberla conducido a esto ni la posibilidad de ligar situaciones, personas y experiencia afectiva.

- Viene a la consulta porque le fue sugerido por un abogado que una evaluación psicológica podía ser conveniente para que eventualmente consideraran devolverle la tenencia de su hijo.

- Falta reiteradamente a las horas asignadas.

No completa el proceso.

\section{ANÁLISIS}

Mi primer encuentro con Patricia quedó marcado por la frase que leí en la hoja de derivación: «Intento de filicidio». Es como si algo en mi interior hubiera comenzado a desmoronarse y sentía que no podría acompañar a esta paciente, que ya se comunicaba sin dificultades con su fuerte e imperante voz. Se refería fundamentalmente al fallecimiento de Camila. Su lamento y su protesta ofuscada se relacionaban con ese hecho penoso. Pero no aparecía mención alguna de su hijo menor ni de los acontecimientos vinculados a la causa judicial que la implicaba. 
Su discurso sin vacilaciones, contundente, no dejaba casi margen para preguntas; su presencia se imponía.

Simultáneamente yo percibía que mis ideas se diluían antes de concretarse en un pensamiento medianamente lúcido. Lo que podía pensar en un momento me resultaba inasible unos segundos después. Hasta que entendí que no estaba pudiendo amalgamar mis afectos con otras formulaciones del pensar y, claramente, desde ese lugar no podía ni debía intervenir. Mi silencio no solo pretendió favorecer el despliegue del discurso del otro, sino que fue el mejor refugio posible ante aquello que me dejaba sumergida en un impacto indescriptible.

Patricia se expresó sin incomodidad y finalmente insistió en su expectativa de que las conclusiones de este trabajo sirvieran para presentar en el juzgado. Así transcurrió nuestro primer «encuentro», por así llamarlo, y debió pasar un cierto tiempo antes de que yo pudiera escribir algo sobre este caso.

En esa primera entrevista no existí demasiado, digamos. Tampoco existió Juan ni su otra hija Cecilia. La palabra fue destinada básicamente a quien había fallecido, a quien ya no estaba. No a las características de los vivos, de aquellos que sí estaban a su alrededor. Y esa fue la tendencia predominante que se mantuvo en distintas instancias de trabajo. Una situación clínica que, podría decir, primariamente me situó ante la destructividad y sus posibles manifestaciones.

Sin duda, la destructividad, a veces de presencia insoslayable, a veces muy constatable, que podemos ver hoy por hoy expandirse en distintos territorios le plantea un problema al pensar psicoanalítico. Un problema en tanto desafío cuasi filosófico y, al mismo tiempo, muy pragmático. ¿Dónde inscribir las expresiones de destructividad del sujeto cuando se trata de analizar una dinámica intrapsíquica y su interacción con el mundo? ¿Qué términos elegir a la hora de denominar sucesos que a veces nos resultarían innombrables? 
Imposible no recordar a André Green (2014), quien nos deja —casi como legado - una pregunta: ¿por qué las pulsiones de destrucción o de muerte?

Sabemos algo del camino que este autor recorrió en su minucioso estudio y reconsideración conceptual de la pulsión, hasta llegar a anexar a la teoría otros términos, quizás más aprehensibles. Nos ha aclarado que «la pulsión es la matriz del sujeto» (Green y Uribarri, 2015, p. 57), pero que es en relación al objeto que se va a desplegar. La pulsión de vida será conceptualizada desde la denominada función objetalizante (que va de la mano de las investiduras) y la pulsión de muerte, desde su destructividad desobjetalizante.

«La función desobjetalizante [...] hace que el objeto pierda sus características específicas para el sujeto» (Green y Uribarri, 2015, p. 60). Desde esta frase tan plena de sentidos, intentaré que nos aproximemos a aspectos de este material, siguiendo algunos referentes teóricos de un pensador que nunca dejó de ser clínico.

En determinado momento Patricia cuenta, casi con particular orgullo: «Yo costeé todo el velorio de Camila. Le compré el vestido de fiesta [de 15] que ella quería, para que se lo pusieran para el velatorio y la maquillaran. [...] No me quería ir, no la quería soltar». Con esto, la paciente parecía haber asignado el estatuto de lo vivo a la chica muerta. Pero de retorno a su casa, casi deja muerto a su hijo vivo.

En esas circunstancias, Patricia se nos presenta como en una conjugación paradojal: necesita cumplir el deseo de quien ya no existe, pero no puede luego escuchar el deseo de su hijo que clamaba por proximidad y contención. Despliega una suerte de poder ante lo inerte y luego se ubica ella misma como inerte ante el pedido afectivo del otro. Es como si se pudieran visualizar investiduras cruzadas, en estrepitosa permutación radical.

Podríamos preguntarnos: ¿cómo se juega la dimensión objetal en esta organización psíquica en tales circunstancias? 
En sus relatos, Patricia se centra en una pérdida. En una sola. Sin poder concientizar todo lo que iba perdiendo alrededor. Viste de fiesta la muerte; lucha por conservar el objeto externo que ya no existe en tanto tal, pero al precio de hipotecar componentes de la realidad. Entre los mecanismos que se despliegan en extrema defensa, asoma una peculiar forma de la idealización.

Desde Green, la idealización es entendida como investidura pulsional negativizada (resultante del trabajo de lo negativo), que se instala como satisfacción ilusoria y desmiente que se trata de una satisfacción vedada (Navarro, 2016). Es una defensa que crea una ficción y habilita, en este caso puntual, un escenario donde lo ideal se plasma casi absurdamente y rompe coordenadas de tiempo y espacio; idealización que no solo se expresa en pensamiento, sino que precipita en acto, quizás en una toma de poder sobre lo que ya no pertenece a nada ni a nadie. Y el deseo se torna indiscernible: ya no sabemos de qué ni de quién. En ese proceder marcado por el exceso, solo puede comprenderse la alteración de la significación, la confusión, la tensa incrustación de algún sentido, la álgida interfase entre situación y estructura.

Cuesta seguir el destino de las investiduras, que parecen transitar por un momento anárquico. Cuesta visualizar y comprender el estatuto asignado al objeto.

Podríamos hablar de un viraje, de la idealización al desconocimiento objetal. Y quizás, en ambos casos, de una dislocación en la situación objetal, que nos aproxima a las reflexiones sobre la función desobjetalizante.

Un desconocimiento... ¿El de Juan? Un hijo que finalmente sobrevivió en los hechos, pero que no habita ni se instala en el discurso de su madre. Juan recibió de nuestra paciente una medicación psiquiátrica que nunca le fue indicada, tan solo así, sin que mediara algún detenimiento transitorio, lo cual derivó en los hechos de gravedad ya citados. Su pedido 
fue así acallado, su angustia silenciada y su eventual porvenir ni siquiera imaginarizado.

Reflexionemos sobre una dimensión del psiquismo en la que el destino objetal está quizás condicionado por procesos de desinvestidura (pero sin ruptura de la ligazón). La desinvestidura también es entendida como mecanismo defensivo, pero con pobres resultados y una confusión aun mayor en este caso.

Asoman aquí aspectos de un funcionamiento que nos remitiría a los efectos del trabajo de lo negativo, que, tal como Green (2010) advierte, se presenta subvertido en las personalidades fronterizas.

Uno de sus aportes conceptuales es el de lo negativo, no como algo desfavorable, sino como lo ausente, lo que no está presente en cierta dimensión psíquica. Un trabajo de lo negativo, de gran complejidad, que detenta una determinada impronta en las neurosis, mientras que asume otro sesgo en las patologías y «estados en los límites de la analizabilidad» (Green y Uribarri, 2015, p. 30). En estos interviene en la articulación de defensas más precarias incidiendo en la no simbolización, la no continuidad existencial, la representabilidad fallante o no siempre disponible, la escisión; una dinámica impregnada de componentes destructivos, que derivan en el ataque del vínculo con el objeto.

Este caso, el de Patricia, parece ejemplarizante al respecto. Se nos presentaría una manifestación de la desinvestidura objetal, expresión de la destructividad que la condiciona.

En cuanto a la historia de la paciente, sabemos de la falla reiterada en sus vínculos primordiales, de su infancia marcada por la alternancia de uniones extremas repentinas y separaciones caóticas en el núcleo familiar, rupturas que pudo sobrellevar — al parecer — desde el reforzamiento de mecanismos omnipotentes. Ciclos vinculares similares se reiteraron después en su curso vital. De aquellas personas que eventualmente se fueron anexando a su historia no contó demasiado. No prioriza descripciones de 
lo que pudo compartir o no con cada quién. Los intercambios se destacaban fundamentalmente desde el aspecto material económico. Su relato transmite su acaecer vital como una serie de sustituciones fácticas, sin mayor especificidad ni dedicatoria, hasta que una gran pérdida la vulnerabiliza más.

Como plantea Green (2014), la pulsión de muerte, que no establece supremacía ni tampoco subordinación respecto a la de vida, no está activa en permanencia. La relación de objeto reclama su lugar decisivo en ese eventual devenir, en tanto es la que hace a la posibilidad de intrincación pulsional, mientras que su fracaso favorece la desintrincación. Son las frustraciones las que introducen el desequilibrio que activa y habilita la expresión de las pulsiones de destrucción.

Este fragmento de teoría nos brinda elementos para pensar lo impensable, para acercarnos a la comprensión de ciertas manifestaciones de la destructividad en determinadas personalidades y de su conexión con los ciclos que recorrerá el objeto, el que se encuentra furtivamente y se vuelve a perder en cada desinvestidura.

Muchas veces nos centramos en el sujeto: su decir, su expresión, su hacer, las manifestaciones de su afectividad, etcétera. Pero no menos importante es el lugar que este asigna a sus objetos. Son quizás los destinos del objeto - ese que a veces silenciosamente se construye, se esculpe, se esconde o se desconoce- los que nos alertan acerca del entramado pulsional establecido y, por tanto, acerca de la organización del psiquismo del sujeto en cuestión.

De mi trabajo con Patricia queda un cúmulo de ideas que aún guardo, de impresiones por articular, de reflexiones, de ligazones, no sé aún si posibles... 


\section{REFERENCIAS BIBLIOGRÁFICAS}

Green, A. (2010). El pensamiento clínico. Buenos Aires: Amorrortu.

GreEn, A. (2014). ¿Por qué las pulsiones de destrucción o de muerte? Buenos Aires: Amorrortu.

Green, A. y Uribarri, F. (2015). Del pensamiento clínico al paradigma contemporáneo. Buenos Aires: Amorrortu.

Navarro, J. B. (2016). Diccionario conceptual André Green. Buenos Aires: Lugar. 